\title{
A PERCEPÇÃO DO DOCENTE NA INCLUSÃO DE ALUNOS COM NECESSIDADES ESPECIAIS NO ENSINO SUPERIOR
}

\author{
TEACHERS' PERCEPTION ON HIGHER EDUCATION INCLUSION OF STUDENTS WITH \\ SPECIAL NECESSITIES
}

\author{
Vanessa Miranda Lidio ${ }^{1}$ \\ Maria Aparecida Bosschaerts de Camargo ${ }^{2}$
}

\begin{abstract}
Resumo: A educação inclusiva é uma realidade e constitui um desafio para o ensino superior. Por isso, não basta adaptações na arquitetura, no material didático e na política educativa. É necessário também que os professores sejam preparados para atender aos alunos com necessidades especiais. Este artigo destaca a importância da capacitação de docentes com respeito ao desenvolvimento pedagógico. O objetivo deste estudo é verificar a percepção dos professores perante a educação inclusiva e a necessidade de capacitação dos mesmos. A pesquisa bibliográfica destacou leis e documentos (Declaração de Salamanca, Lei de Diretrizes e Bases 9394/96, Programa Educação Inclusiva) que conduzem à valorização do treinamento e à busca de informações e recursos para o preparo de docentes que atuam neste campo. Propõe a reflexão sobre a efetivação e sucesso da educação inclusiva, a reorganização curricular das universidades, o incentivo aos cursos, o aperfeiçoamento e a criação de centros de apoio. A pesquisa de campo envolveu doze docentes que lecionam no curso de fisioterapia da Universidade Federal do Triângulo Mineiro, submetidos a um questionário com seis perguntas abertas. A entrevista constatou o despreparo dos docentes para trabalhar com os discentes com necessidades especiais, confirmando a hipótese do presente estudo e destacou o interesse dos participantes por cursos de capacitação.
\end{abstract}

Palavras-chave: Educação inclusiva. Ensino superior. Capacitação de docentes.

Abstract: Inclusive education is a reality, and it constitutes a challenge for higher education. Therefore, adaptations of the architecture, the didactic material and the politics of education are not enough. It is also necessary for teachers to be prepared to assist students with special necessities. This article points out the importance of teachers training regarding pedagogical development. The objective of this study is to verify teachers' perception of inclusive education and the necessity of training them. Our bibliographical survey focused in laws and documents (Declaration of Salamanca, Law of Guidelines and Bases 9394/96, Program for Inclusive Education) that lead to the valuation of training and the search of information and resources for the preparation of teachers who act in this field. It proposes to reflect on the effectiveness and success of inclusive education, the curricular reorganization of universities, encouragement to courses, the improvement and the creation of support centers. The field research involved twelve teachers who teach in the course of physiotherapy of the Federal University of Triângulo Mineiro, submitted to a questionnaire with six open questions. The interview showed how unprepared are teachers to work with students with special necessities, confirming the hypothesis of the study, and it also emphasizes the interest participants have for training courses.

Keywords: Inclusive education. Higher Education. Teachers training. Introdução

1 Aluna do Curso de Especialização em Docência na Educação Superior da Universidade Federal do Triângulo Mineiro, vanessalidio@hotmail.com.

2 UNIESP - Faculdade de Presidente Prudente, Professora convidada da universidade Federal do Triangulo Mineiro, curso de pós-graduação em Docência na Educação Superior da Universidade Federal do Triângulo Mineiro. cidaboss1@terra.com.br. 
O presente artigo aborda a importância da capacitação de docentes ao desenvolvimento pedagógico para alunos com necessidades especiais no ensino superior, cuja inclusão baseia-se na reestruturação arquitetônica das instalações físicas, reformulação de material didático específico às demandas e política de educação e principalmente treinamento aos docentes para atender de forma adequada aos alunos com estas necessidades educativas. Não basta matriculá-los e sim dar-lhes condições de acesso e permanência. No processo da graduação e pósgraduação lato sensu e stricto sensu, todavia, não se ensina como trabalhar com a diversidade na sala de aula; não consideram a realidade que o futuro professor irá enfrentar. Com base em Linhares e Trindade (2003), a inclusão de todos é uma evidência e não um mito, logo, não só os alunos, mas as instituições e os professores precisam de apoio. Então, é viável a percepção dos docentes perante a educação inclusiva e ressaltar a necessidade de recursos a própria capacitação.

A educação inclusiva é a atenção à diversidade; segundo Guimarães (2002), para ser respeitada e valorizada, a instituição educativa tem que definir sua responsabilidade nas relações, as quais envolvem os profissionais em um amplo processo de discussão, estudo e reflexão sobre a inclusão. Não é correto ver a carreira de professor como vocação e sim como profissão que precisa de muito estudo, muita reflexão e uma prática realmente transformadora. Holly (2000) explica que o conteúdo do professor profissional tende a relacionar-se com a vida quotidiana, com os acontecimentos mundiais; com a relevância, o interesse e a curiosidade e com as diferenças individuais dos alunos. Portanto, as tarefas do docente exigem flexibilidade, maturidade psicológica, criatividade e complexidade cognitiva.

A Declaração de Salamanca (1994) diz que as instituições devem prover oportunidades curriculares apropriadas a pessoa com habilidades e interesses diferentes. E a Lei de Diretrizes e Bases n. 9394 (BRASIL, 1996) exige que as universidades contribuam para o ingresso dessas pessoas. Tanto a Declaração quanto a Lei 9394 consideram primordial o treinamento dos docentes para buscar novas informações e recursos, de forma a atender as necessidades dos discentes com necessidades especiais.

Destacam-se referências sobre a preocupação com a relação professor/aluno com necessidade especial. De acordo com Rehder e Oscar (2007), ao avaliarem a 
capacitação de quinhentos docentes para o ensino aos alunos com necessidades especiais, constataram-se que $96 \%$ dos docentes do ensino público consideram-se despreparados, sendo que $87 \%$ não tiveram qualquer treinamento específico. De forma análoga, Vitalino (2007) aborda o despreparo da maioria de docentes de diversos níveis de ensino ao atendimento de alunos portadores de necessidades especiais.

Diante disso, Vitalino (2007) afirma que, para alcançar o êxito da educação inclusiva, as instituições devem centralizar esforços na educação e treinamento de docentes, no desenvolvimento de materiais didáticos específicos e nas avaliações contínuas de docentes, e também dos alunos com necessidades especiais, de forma a inferir o grau de eficiência. E a partir daí propor políticas de educação continuada para o atendimento adequado e satisfatório das necessidades demandadas.

A educação sofreu e sofre mudanças. No momento, para Zulian e Freitas (2007), o educador caracteriza-se por ter uma visão ampla e crítica das novas formas de aquisição do conhecimento e das novas tecnologias da informação e comunicação, obtendo assim qualidade de educação e vida. A educação contribui para a formação do educando com várias competências, torna-o capaz de fazer escolhas, compreender a sua realidade e refletir sobre ela.

A Lei 9394/96, que rege a educação no país, estabelece, no artigo 58: "Entende-se por educação especial, oferecer ensino para educandos portadores de necessidades especiais.". Desta forma, ela procura assegurar educação para todos e reforçou o movimento de inclusão. Em relação a esse movimento, Sassaki (1997) afirma:

A inclusão social é o processo pelo qual a sociedade e o portador de deficiência procuram adaptar-se mutuamente tendo em vista a equiparação de oportunidade e, conseqüentemente, uma sociedade para todos. A inclusão (na sociedade, no trabalho, no lazer, nos serviços de saúde, etc.) significa que a sociedade deve adaptar-se às necessidades da pessoa com deficiência para que esta possa desenvolver-se em todos os aspectos de sua vida (SASSAKI, 1997, p.168).

Para Zulian e Freitas (2007), os avanços científicos e tecnológicos têm proporcionado mudanças no aspecto político, social e educacional, responsáveis pelo surgimento de instrumentos de inclusão de pessoas com necessidades educativas especiais nas instituições de ensino superior. Principalmente após a 
Conferência Mundial de Educação para todos e da Declaração de Salamanca, a inserção tornou-se discussão mundial e promoveu uma revolução educacional.

Vale ressaltar que para Zulian e Freitas (2007), a inclusão implicou a formação de professores e propostas de ensino, não permitindo o preconceito e discriminação, mas sim, estimulando a interação de todos com o mundo e a promoção da auto-estima do aluno especial. Destaca-se a preocupação com a formação e qualificação de profissionais porque, ao se referir à educação inclusiva, o professor deve estar preparado para desafios e propor soluções, como promover a integração de grupos, a partir da conscientização e aceitação das diferenças individuais, valorização de cada pessoa, convivência dentro da diversidade humana e aprendizagem por meio de cooperação.

Gadotti (1992) explica que a equidade em educação significa igualdade de oportunidades para todos poderem desenvolver suas potencialidades, e educação para todos significa acesso de todos à educação. Então, as pessoas com necessidades especiais têm o direito à educação, que está em consonância com a Declaração Universal dos Direitos Humanos, que diz: "Todo ser humano tem direito à educação." Essa foi a primeira diretriz política surgida, seguida de outras leis, que são elaboradas para garantir o direito ao acesso das pessoas à educação, conforme Sassaki (1997).

Segundo Santos (2005), no século $X X$, as pessoas com necessidades especiais passam a serem vistas como cidadãos, com direitos e deveres. Para compreender essa afirmação, é necessário explanar a história da educação especial no Brasil. Foi em 1961 que a educação especial foi citada em na Lei de Diretrizes e Bases. A educação inclusiva começou a ser defendida em larga escala a partir da década de 70.

Mas foi na década de 80, segundo Sassaki (1997), que ocorreu o impulso da prática da integração social, com o surgimento da luta pelos direitos do deficiente físico e a inclusão, pois ao final dos anos 90 percebeu-se que a integração social era insuficiente para acabar com a discriminação e para propiciar a verdadeira participação plena, com igualdade de oportunidades. "Da exclusão social total passando para o atendimento especializado segregado e depois para a integração social, o segmento dos portadores de deficiências está agora lutando por sua inclusão social." (Sassaki, 1997, p.16). 
A Constituição Federal de 1988 garante educação especializada aos portadores de deficiência visual, auditiva e física. Para Santos (2005), na década de 90 a inclusão cresceu com a finalidade de formar cidadãos conscientes e participativos, exigindo mais leis que assegurem a educação aos alunos com necessidades especiais. Assim, surgiu a Lei n. 9394 (BRASIL, 1996), com destaque para o artigo 59, que assegura aos alunos:

I -currículos, métodos, técnicas, recursos educativos e organização específicos, para atender às suas necessidades, II - terminalidade específica e III - professores com especialização adequada em nível médio ou superior, para atendimento especializado, capacitados para a integração desses educandos nas classes comuns. (BRASIL, 1996, art.59)

Gadotti (1992) destaca a Conferência Mundial sobre Educação para Todos, realizada na Tailândia em 1990, que foi convocada pelo Fundo das Nações Unidas para a Infância (UNICEF), pelo Programa das Nações Unidas para o Desenvolvimento (PNUD), pela Organização das Nações Unidas para a Educação, Ciência e Cultura (UNESCO) e pelo Banco Mundial, tendo como tema central Educação para todos.

Na Conferência, segundo Gadotti (1992), estabeleceram-se os fundamentos de uma política educacional mundial e foram aprovados documentos como a Declaração Mundial sobre Educação para todos, de1990, e a Declaração de Salamanca, de 1994, com princípios de reformulação do sistema de ensino e ênfase na inserção social como forma mais efetiva da implantação da educação inclusiva.

Em 2003 teve início o Programa Educação Inclusiva do Ministério da Educação, explicitado no documento "Direito à Diversidade para proporcionar uma educação de qualidade", publicado pela Secretaria de Educação Especial, em 2006. Tal programa tem como objetivo expandir a política da educação inclusiva e amparar a formação de gestores e educadores. Ao implantá-lo, melhoraram as condições de acesso e permanência na escola. Vários projetos foram criados; em 2004, o Projeto Educar na Diversidade, para formação e acompanhamento de docentes; em 2006, o Ministério da Educação, a Secretária da Educação Especial e o Programa das Nações Unidas para o Desenvolvimento realizaram a formação de gestores e educadores, onde o princípio foi a universalização do acesso à educação e na atenção à diversidade. 
Castanho e Freitas (2005) ressaltam que, a partir das políticas de inclusão, ficou inevitável a preparação da instituição e do docente para receber os alunos com necessidades especiais. A discussão sobre educação inclusiva é recente e constituise num desafio para o ensino superior, pois se refere ao desconhecido. Todavia, a implementação de ações educativas junto a estudantes com necessidades especiais nesse ensino é uma atitude democrática e uma questão de cidadania. Em entrevistas a docentes ficou evidente que a prática não se coaduna com toda a legislação referente à inclusão de pessoa com necessidade especial.

A universidade contribui socialmente com a produção de conhecimento, para promover o desenvolvimento da cultura, da ciência, da tecnologia e do próprio homem como indivíduo na sociedade. É o meio para a produção do conhecimento científico e para o avanço tecnológico, portando, é responsável pela promoção da cidadania e possui o dever de oportunizar e incentivar uma educação para todos, afirma Castanho e Freitas (2005).

Segundo Pacheco e Costas (2005) a lei protege as pessoas com necessidades especiais, desde a educação elementar até ao ensino superior. Uma instituição, para receber a autorização e reconhecimento de cursos, como também o credenciamento, tem como dever a acessibilidade aos deficientes. O Ministério da Educação e a Secretária da Educação Especial estimularam a política de construção de sistemas educacionais inclusivos, implantaram o Programa Educação Inclusiva nos municípios brasileiros, firmaram convênios, parcerias e distribuíram equipamentos, mobiliários e material pedagógico.

De acordo com o Ministério da Educação (2007), a inclusão significa transposição de barreiras e fortalecimento de novos paradigmas educacionais ao atendimento de diferentes necessidades; este é um dos espaços de ação e de transformação, que conjuga a idéia de políticas educacionais e sociais amplas, garantindo os direitos de todos. Entretanto, percebe-se que faltam ainda recursos, principalmente humanos para que todos estes direitos alcancem os verdadeiros interessados.

As universidades brasileiras devem reorganizar as grades curriculares para atenderem aos aspectos legais, como a Portaria n. 1793 (BRASIL, 1994) que recomenda a necessidade de complementar os currículos de formação de docentes e a inclusão da disciplina aspectos ético-político-educacionais da Normalização e Integração da pessoa com necessidades especiais nos cursos do grupo de Ciência 
da Saúde, no de Serviço Social e nos demais cursos superiores e a Lei 9394 (BRASIL, 1996), art. 63 que diz: "Os institutos superiores de educação manterão: III - programas de educação continuada para os profissionais de educação dos diversos níveis."

Castanho e Freitas (2005) consideram que o docente necessita de capacitação, ou seja, um preparo para garantir o desenvolvimento de habilidades e conhecimentos necessários a uma ação segura. É importante a formação e qualificação de professores, para atuarem frente à diversidade e desempenhar uma educação de qualidade. É indispensável o treinamento e acompanhamento de professores, pois a educação inclusiva terá sucesso se todos os envolvidos, universidade e professor, forem responsáveis nas atitudes e valores (Vitalino, 2007).

Zulian e Freitas (2007) destacam que o professor, ao deparar com o aluno deficiente, pode ignorar o processo de mudança, por insegurança ou preconceito e devido à falta de informação. Pode, por outro lado, aceitar, avaliar as competências curriculares e habilidades do aluno, para poder elaborar uma proposta de intervenção diversificada que beneficie e atenda necessidades educacionais do discente. A interação no ambiente enriquece a capacidade intelectual, a auto-estima e autonomia do aluno, que irá aprender e se desenvolver cognitiva, emocional e socialmente.

A inclusão no ensino superior exige rupturas e busca de alternativas e formação do professor e práticas educativas diferenciadas, voltadas ao uso das novas tecnologias da informação e comunicação. Por isso, nas instituições, é necessário haver uma postura política de aceitação das diferenças e conhecimentos técnicos, para que os docentes trabalhem com os alunos especiais. Para Santos (2005), deve haver uma organização pedagógica, arquitetônica, física e administrativa, para garantir os mesmos direitos, a mesma liberdade que aos demais, e evitar a exclusão, que ocorre pela falta de tradutores de Libras, de espaços adaptados, de professores com cultura de aceitação e tentativa em restringir espaços para as pessoas com deficiência.

Mena (2004) destaca que a formação e o aperfeiçoamento do professor na prática pedagógica de deficientes passa a ser uma construção contínua. Santos (2005) afirma que o professor assume característica de mediador, pesquisador e motivador, tornando-se um colaborador que reconhece e aceita a diversidade, preparado para enfrentar desafios e propor soluções, para que o aluno tenha as 
mesmas oportunidades. Este aluno deve participar ativamente do processo de aquisição e construção de conhecimentos; assumir responsabilidade e elaborar seus projetos de vida. O professor terá de ser sensível às diferenças, atento à dinâmica e às demandas de cada grupo-classe como um todo, e aos limites e possibilidades de cada aluno, singular, porém igual, semelhante em direitos, deveres e valores.

A formação dos professores, de acordo com Pacheco e Costas (2005), é um fator indispensável à realização da inclusão, que requer medidas que facilitem e auxiliem a concretização da mesma, além da adequação de recursos pedagógicos, assessoria psicopedagógica e criação de comissões ou centros de apoio na própria instituição. $O$ fato de que o ensino superior é cada vez mais acessível às pessoas com necessidades especiais, torna a capacitação do docente a grande contribuição, que possibilita resultado positivo ao sucesso da inclusão; passar por um treinamento poderá proporcionar aos professores atitudes e emoções favoráveis à inclusão. De acordo com o Ministério da Educação (BRASIL, 2005), a educação inclusiva exige mudanças nos recursos e no meio, com aquisição de equipamentos, reforma estrutural e apoio a programas de acesso e permanência.

Também são necessárias mudanças nos processos de gestão, nas metodologias educacionais e de igual importância, na capacitação dos docentes, bem como uma reflexão para efetivação e sucesso da inclusão de pessoas com necessidades especiais na educação superior; a realização de cursos, palestras com os docentes para aperfeiçoar suas habilidades práticas no acompanhamento pedagógico de deficientes. É imprescindível ainda formar centros de apoio aos alunos e aos professores nas universidades. A inclusão é uma realidade, as instituições devem proporcionar atendimento de apoio, pesquisa, assessoria, referência e formação para professores.

\section{Desenvolvimento}

Para o presente artigo foi feito estudo descritivo com abordagem qualitativa. Como salienta Minayo (1993) o sujeito do estudo, na pesquisa qualitativa, aquele que em determinada condição social, pertence a um grupo social ou classe, caracterizada com suas crenças, valores e significados. $O$ sujeito pode ser contraditório e em permanente transformação; a pesquisa qualitativa precisa de um referencial de coletas. Ela visa a compreender os valores culturais de um grupo 
sobre temas específicos, avaliar as políticas públicas e sociais na sua formulação, os usuários a quem se destina e aplicação técnica. Tem uma etapa essencial que é o trabalho de campo, no qual é importante a interação entre o pesquisador e os sujeitos pesquisados.

A Universidade Federal do Triângulo Mineiro foi o local escolhido para a realização do estudo, em que se propõe verificar a percepção do docente na inclusão de alunos com necessidades especiais no ensino superior. Os sujeitos da pesquisa foram doze docentes, de ambos os sexos, todos maiores de 18 anos, do curso de fisioterapia da Universidade Federal do Triângulo Mineiro, de Uberaba, Minas Gerais. Foram entregues a eles um termo de consentimento e um questionário com 06 questões abertas, para serem respondidas por escrito.

Sendo uma entrevista feita através de questionário aplicado diretamente pelo pesquisador, segundo Minayo (1993), trata-se de uma entrevista estruturada. Foram abordados os itens: se o docente teve ou tem aluno com necessidades especiais e qual a deficiência; se teve, tem ou terá dificuldade no relacionamento; se está preparado para aceitar e trabalhar com aluno especial em sua sala de aula; se está capacitado para atender esse aluno; se tem conhecimento de cursos de capacitação para docentes sobre a Educação Inclusiva nas Universidades, se acreditam que teriam demanda para esses cursos e ainda se haveria interesse pessoal em freqüentá-los.

A intenção da pesquisa foi exposta aos docentes e foi solicitado o preenchimento do questionário, que se daria de forma manual em sua própria, com tempo de dez minutos para esclarecimento da pesquisa e trinta minutos para o preenchimento do questionário. Aos participantes do estudo foram assegurados o anonimato e a privacidade como também o direito de não responderem ao questionário; não houve, porém, nenhuma rejeição.

O material foi organizado a partir da coleta dos dados descritivos e analisado seguindo o processo indutivo. Segundo os critérios das abordagens com base no referencial teórico da área educacional, que teve por base as respostas contidas nas seis perguntas do questionário realizado, de acordo com Minayo (1993). 


\section{Resultados e Discussão}

A primeira pergunta feita aos docentes foi: você tem ou teve aluno com necessidades especiais? Qual a deficiência ele apresentava?

\section{Grafico 01}

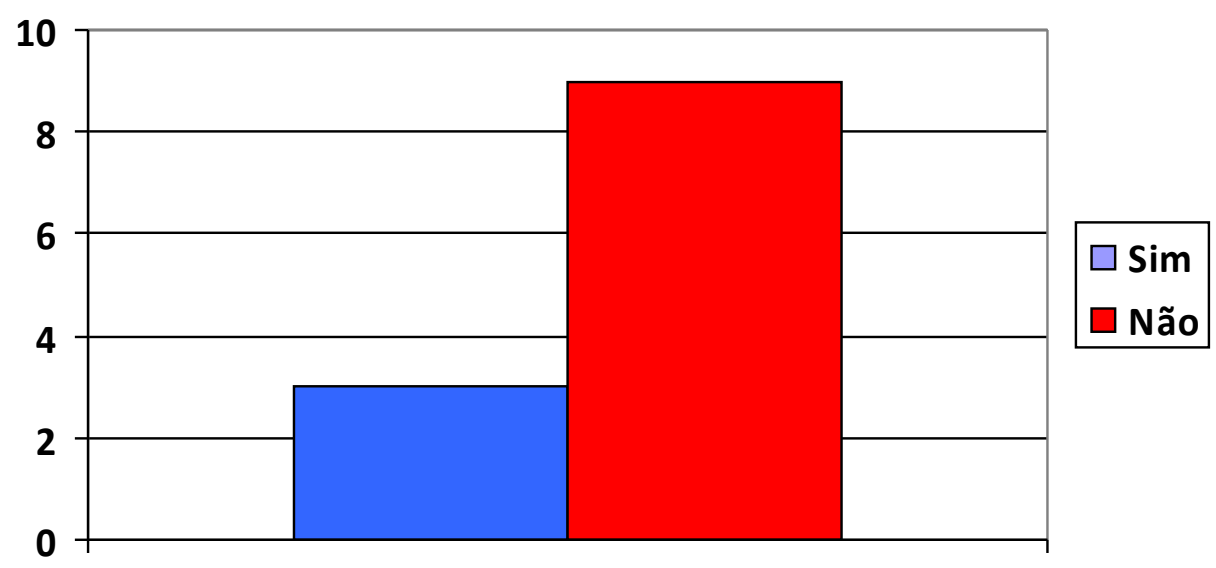

Docentes

Três docentes responderam que sim. Um professor relatou ter tido dois alunos com deficiência: um apresentava deficiência motora, devido seqüela de Paralisia Cerebral; e o outro tinha deficiência visual. Outro professor disse ter tido um aluno com deficiência auditiva e o terceiro docente teve um aluno com deficiência visual. Os outros nove responderam que não tiveram alunos com necessidades especiais.

A segunda pergunta era: que tipo de dificuldade você tem, teve ou imagina que teria, ao relacionar-se com esse aluno?

As respostas obtidas foram:

O professor que teve dois alunos especiais não teve dificuldade de relacionamento com os mesmos, mas preocupou-se em como trabalhar durante a execução da prática clínica; outro docente disse que não podia responder; um professor respondeu que há dificuldades no ensino, como a não adaptação do ambiente físico, no material didático e do docente; o docente que teve aluno com 
deficiência auditiva disse que encontrou dificuldades relacionadas ao entendimento da matéria, pois o aluno, por vergonha de demonstrar suas limitações, não questionava; um professor respondeu que depende da deficiência, ele teria uma maior dificuldade didática com alunos portadores de deficiência cognitiva; outro disse que teria dificuldade de interagir pela linguagem; um docente respondeu que a dificuldade estaria na integração a sua disciplina, anatomia; outro declarou que teria dificuldade em lidar com alunos com deficiência auditiva; outro respondeu que a dificuldade seria relacionada ao tipo de deficiência, no âmbito pessoal acredita que não teria problemas; dois professores disseram que isso dependeria da deficiência; um teria de conhecer mais a fundo a deficiência do aluno e o outro teria dificuldade com os déficits sensoriais ou de integração sensorial. Como os dois docentes anteriores, outro professor respondeu que dependeria da deficiência, que poderia ter dificuldades relacionadas a especificidade de cada disciplina do curso e as habilidades motoras e cognitivas exigidas para o aprendizado.

A pergunta seguinte indagou: Como docente universitário, você está, esteve ou imagina que estaria preparado para aceitar e trabalhar com um aluno especial em sua sala de aula?

A seguir, as respostas.

Um respondeu que com muita dedicação seria possível trabalhar; o professor que já teve experiência em lecionar para alunos especiais disse que buscou respeitar as particularidades de cada um, porém não se sente preparado; um disse que deveria haver programas de capacitação específicos; outro respondeu que está preparado para aceitar, mas necessitaria de um treinamento; um próximo docente disse que não se considera apto, encontraria problemas; um respondeu que dependeria da deficiência; quatro docentes responderam sim, porém não estão preparados; um disse não; outro respondeu que não está preparado, teria dificuldades em lidar com a comunicação com alunos com deficiência visual e auditiva. 
A quarta pergunta foi: Você está capacitado para atender um aluno com deficiência física?

Gráfico 02

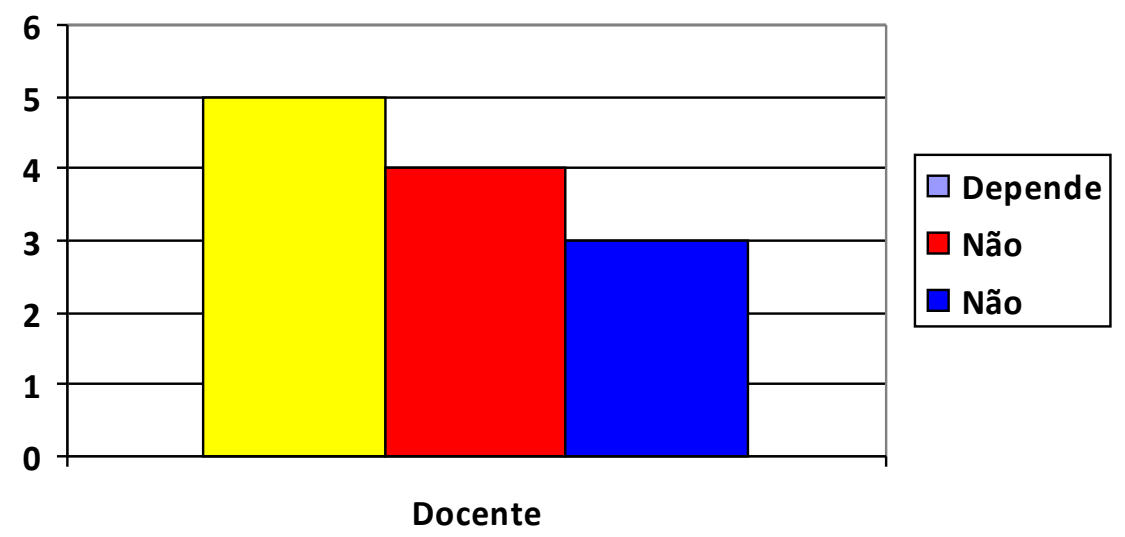

Cinco responderam que depende da deficiência, quatro disseram não e três afirmaram que estão capacitados.

A próxima questão interrogou: Você tem conhecimento de cursos de capacitação para docentes sobre a educação inclusiva nas universidades?

Gráfico 03

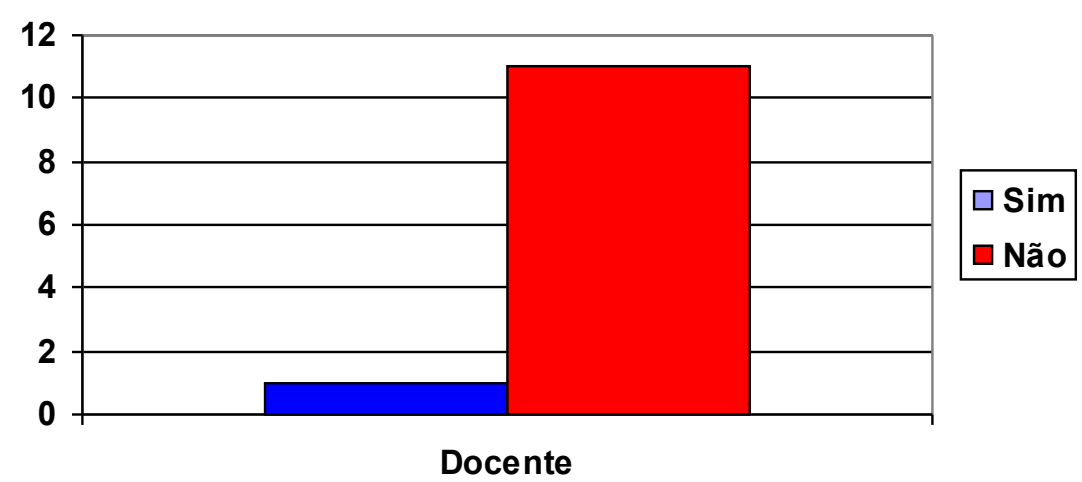

Um professor disse sim e onze disseram não. 
A última pergunta foi: Você imagina que haveria demanda para eles? Gostaria de ter acesso a estes cursos?

\section{Gráfico 04}

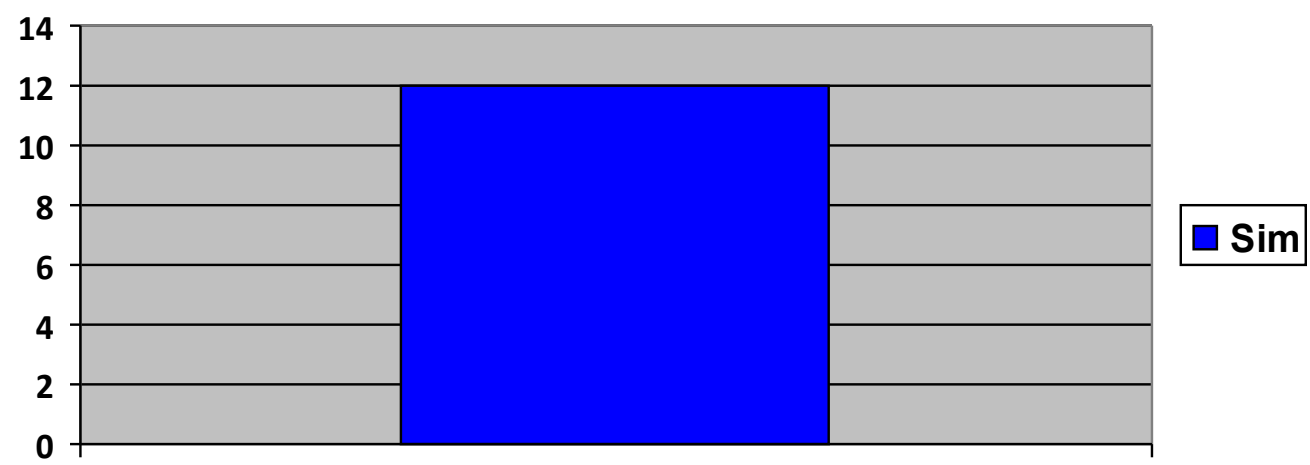

Docente

A resposta foi unânime, os 12 responderam sim.

Ao analisar as respostas do questionário aplicado aos docentes do curso de fisioterapia da UFTM, observamos que a capacitação dos docentes é inevitável para o sucesso da educação inclusiva, pois a maioria dos entrevistados se sente despreparado para atender os discentes com necessidades especiais. Nosso estudo vem ao encontro dos anseios de Rehder e Oscar (2007) e Vitalino (2007), no sentido de mostrar que há necessidade de treinamento aos docentes do ensino superior.

A pesquisa concluiu que a percepção dos docentes, ao se depararem com um aluno com necessidades especiais, é de despreparo, de insegurança frente ao desconhecido. O processo da educação inclusiva, portanto, não só deve estar atento ao aluno, mas em igual importância deve ter preocupação e atenção com os docentes que irão atendê-los nas universidades.

Analisando as respostas dos professores, constatou-se que as dificuldades encontradas estariam relacionadas com o tipo de deficiência; para alguns seria mais complicado lidar com problemas auditivos, para outros com os cognitivos. Aceitar o aluno em sala de aula não é um obstáculo, porém trabalhar com esses alunos é o que se torna uma dificuldade, necessitando de um preparo.

No que refere à participação em curso de capacitação, observamos que todos os professores entrevistados têm interesse em participar. A educação inclusiva gera 
expectativas, dúvidas, sendo de importância a criação de uma comissão de apoio para promover auxílio no processo de inclusão, como as que existem na Universidade do Vale do Itajaí, Santa Catarina e a Comissão Permanente de Apoio ao Portador de Necessidades Especiais, da Universidade Federal de Minas Gerais, citadas por Pacheco e Costas (2005).

\section{Conclusão}

A pesquisa atendeu aos objetivos propostos, verificou-se a necessidade de capacitação do docente para o benefício da educação inclusiva no ensino superior; ressaltou a importância da habilitação específica e verificou a percepção dos professores perante a educação inclusiva. Confirmou-se a hipótese do despreparo dos docentes. Identificou-se o interesse em participar de cursos de capacitação, que são desconhecidos dos docentes entrevistados, e a pouca divulgação de tais cursos.

A pesquisa constatou a existência de material, informações e leis sobre a educação inclusiva. Comprovou e salientou a importância da formação de professores aptos ao processo de inclusão de alunos com necessidades especiais, uma vez que não recebem esse preparo em sua graduação. Essa preparação inclusiva não só a graduação em fisioterapia, mas a formação pedagógica e didática.

Atestamos que para efetivação da educação inclusiva, além das adaptações arquitetônicas e didáticas, também deve haver docentes preparados nas universidades. O processo da educação inclusiva requer continuidade, motivando a criação de comissões de apoio aos profissionais; sistema de parceria com instituições que já possuem esses apoios, para desenvolver cursos, palestras e treinamentos.

Acreditamos que a consolidação da educação inclusiva ocorrerá gradual e lentamente nas universidades e se expandirá para pós-graduação e para toda a sociedade. As instituições devem contribuir socialmente, dando acessibilidade à inclusão, para que forme futuros profissionais que venham a auxiliar na construção de uma sociedade verdadeiramente igualitária.

Entende-se então que a inclusão de pessoas com necessidades especiais enfrenta vários desafios. A formação de professores já discutida anteriormente, a autonomia das universidades em eleger o tipo de deficiência do aluno, entretanto essa deficiência diverge da condição de democratização e acessibilidade de ensino 
a todos, porém deve haver de caso a caso, ao conhecer a limitação e analisar a possibilidade de aluno concluir o curso e exercer profissão.

Um dos desafios mais importantes seria a capacidade do educador de acolher e desenvolver as habilidades de cada um em sala de aula e/ou mesmo na aula prática, e ainda de que ambos, professor e aluno, construam as condições para que o processo ensino - aprendizagem se efetive.

\section{Referências}

BRASIL. Ministério da Educação. Lei n. 9394, de 20 de Dezembro de 1996. Disponível em: <http://portal.planalto.gov.br/ccivil_03/leis/9394.htm>. Acesso em 12 jul. 2007.

. Ministério da Educação. MEC investe na inclusão de alunos especiais em universidades. Secretaria de Educação Especial, 2005. Disponível em: <http:// portal.mec.gov.br/seesp/index.php?

option=com_content\&task=view\&id=2593\&Interna=6>. Acesso em: 12 jul. 2007.

. Ministério da Educação. Portaria n. 1793 - Formação dos Docentes na Educação Especial, 1994. Disponível em: <http://portal.mec.gov.br/seesp/ arquivos/ pdf/port1793.pdf>. Acesso em: 12 jul. 2007.

- Ministério da Educação. Programa Educação Inclusiva: Direito à Diversidade. Secretaria de Educação Especial, 2006. Disponível em: <http://portal.mec.gov.br/seesp/index.php?option=content\&task=view\&id=67\&ltemid =196>. Acesso em: 12 jul. 2007.

CASTANHO, D. M.; FREITAS, S. N. Inclusão e prática docente no ensino superior. Centro de Educação. Revista Brasileira de Educação Especial, Santa Maria, RS, caderno 2005, n. 27. Disponível em: <http://coralx.ufsm.br/revce/ceesp/2006/01/r6. htm>. Acesso em: 20 mar. 2008.

DECLARAÇÃO DE SALAMANCA, 1994. Disponível em: <www.educacaoonline. pro.br/doc_decl_salamanca.asp?f_id_artigo=3>. Acesso em: 18 mar. 2008.

GADOTTI, M. Diversidade cultural e educação para todos. Rio de Janeiro: Graal, 1992.

GUIMARÃES, T. M. (org). Educação Inclusiva: construindo significados novos para a diversidade. Belo Horizonte: Secretaria do Estado de Educação de Minas Gerais, Lições de Minas, v. XXII. 2002.

HOLLY, M. L. Investigando a vida profissional dos professores: diários biográficos. In: NÓVOA, A. Vidas de professores. Porto: Porto, 2 ed., 2000, cap. IV, p. 79 -110. 
MINAYO, M. C. de S. O desafio do conhecimento: pesquisa qualitativa em saúde. 2. ed. São Paulo: Hucitec, 1993.

MENA, F. Inclusão exige capacitar os professores. Assessoria de Comunicação e Imprensa da UNICAMP. Disponível em: <www.unicamp.br/unicamp/ canalaberto/ clipping/ fevereiro2004/clipping040222_folha.html-21k>. Acesso em: 13 jan. 2008.

NADDE, S. A. S. de O.; GARCIA, N.; MACHADO, E. V. Centro de Apoio Acadêmico aos Deficientes. Associação Brasileira de Mantenedoras do Ensino Superior. Disponível em: <www.abmes.org.br/publicacoes/Cadernos/06/unicid.htm32k>. Acesso em: 13 jan. 2008.

PACHECO, R. V.; COSTAS, F. A. T. O processo de inclusão de acadêmicos com necessidades educacionais especiais na Universidade Federal de Santa Maria. Centro de Educação da Universidade Federal de Santa Maria. Revista Brasileira Educação Especial, RS, caderno 2005, n. 27. Disponível em: <http://coralx.ufsm. br/revce/ceesp/ 2006/01/a12.htm>. Acesso em: 02 mar. 2008.

PEÇAS, A. Uma Escola Acolhedora, uma Educação Inclusiva. In: LINHARES, C. e TRINDADE, M. N.(orgs). Compartilhando o Mundo com Paulo Freire. São Paulo: Cortez, v.7, 2003. cap. 07, p. 137-145.

REHDER, M.; OSCAR, N. Professor não está preparado para alunos deficientes. O Estado de São Paulo. São Paulo, 02 dez, 2007, Vida\&, p. A40.

SANTOS, A. R. F. dos. et al. O professor e a inclusão. Educação Inclusiva. Sociedade brasileira de referência em educação inclusiva. Guarujá, 2005. Disponível em: <www. sobrei.org.br/sobrei/mostraArtigo.asp?idArtigo=253-18k>. Acesso em: 12 jul. 2007.

SASSAKI, R. K. Inclusão - Construindo uma sociedade para todos. Rio de Janeiro: WVA, 1997.

VITALINO, C. R. Análise da necessidade de preparação pedagógica de professores de cursos de licenciatura para inclusão de alunos com necessidades educacionais especiais. Revista Brasileira Educação Especial, caderno 2007, v. 13, n. 03. Disponível em: <http://www.scielo.br/ scielo.php?script=sci_abstract\&pid= S1413$653200700300007 \&$ Ing=pt\&nrm =iso\&lng=pt>. Acesso em: $19 \overline{m a r}$. 2008.

ZULIAN, M. S.; FREITAS, S. N. Formação de professores na educação inclusiva: aprendendo a viver, criar, pensar e ensinar de outro modo. Centro de Educação. Revista Brasileira de Educação Especial, Santa Maria, RS, caderno 2001, n.18. Disponível em: <http://coralx.ufsm.br/revce/ceesp/2001/02/ r5. htm>. Acesso em: 12 jul. 2007.

Recebido para publicação em: 14/08/2008

Aceito: $20 / 12 / 2008$ 